\title{
Efficacy of Pneumatic Retinopexy in Treating Rhegmatogenous Retinal Detachment at King Abdullah Medical City in Makkah, Saudi Arabia - A retrospective cohort study
}

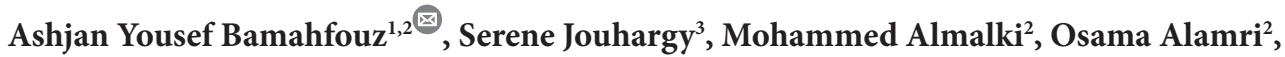 \\ Raed Alsulami ${ }^{4}$, Saeed Alzahrani ${ }^{5}$, Ahmad Himayda ${ }^{1}$ \\ ${ }^{1}$ Faculty of Medicine, Umm Al-Qura University, Makkah, Saudi Arabia \\ ${ }^{2}$ King Abdullah Medical City, Makkah, Saudi Arabia \\ ${ }^{3}$ Basafar Eye Centre, Jeddah, Saudi Arabia \\ ${ }^{4}$ Jeddah Eye Hospital, Jeddah, Saudi Arabia \\ ${ }^{5}$ King Saud University, Jeddah, Saudi Arabia
}

\section{ABSTRACT}

Introduction: The aim of this study was to present the clinical presentation and short-term outcomes of uncomplicated rhegmatogenous retinal detachment managed by pneumatic retinopexy at a tertiary eye hospital in western Saudi Arabia.

Materials and methods: This one-armed retrospective cohort study evaluated selected cases of rhegmatogenous retinal detachment managed by pneumatic retinopexy between 2017 and 2018. Data were collected on patient demographics, preoperative ophthalmic assessment, surgical details, follow up at six months postoperatively, complications and the need for additional surgery. Anatomic success was defined as retinal attachment at 6 months and functional success was defined as vision $>20 / 200$ at six months postoperatively. The association of lens status and concomitant laser treatment to anatomical success rates were evaluated.

Results: The study sample consisted of 15 eyes with rhegmatogenous retinal detachment in the upper quadrant. In 14 cases, C3F8 gas was used. Anatomic and functional success was noted in 73.3\% [ $95 \%$ confidence interval (CI) 51.0: 95.7] and 86.7\% (95\% CI 69.2; 100) of eyes, respectively. The association between anatomical success and lens status was not significant $[\mathrm{RR}=4.5(95 \% \mathrm{CI} 0.6 ; 37.5), \mathrm{P}=0.1]$. There was no significant association between anatomical success and concomitant laser treatment. [RR $=\mathrm{RR}=1.7(95 \% \mathrm{CI} 0.7 ; 4.0), \mathrm{P}=0.2]$. A 2 nd retinal surgery was not required in $33.3 \%$ of eyes $(95 \% \mathrm{CI}$ $9.5 ; 57.2)$.

Conclusion: If stringent selection criteria are used for managing rhegmatogenous retinal detachment with pneumatic retinopexy, anatomical and functional success by six months postoperatively is achieved in the majority of cases. Additional surgeries could further improve outcomes.

Key words: Gas tamponade; Pneumatic retinopexy; Retinal breaks; Retinal detachment.

Financial Interest : Nil Recei
Conflict of Interest : Nil Accep
Corresponding Author
Dr. Ashjan Yousef Bamahfouz
Faculty of Medicine, Umm Al-Qura University,
Makkah, Saudi Arabia.
E-mail: ashjanmd@gmail.com
Contact: +966547777059

Received : 19.08.2020

Accepted : 12.04.2021
Access this article online

Website: www.nepjol.info/index.php/NEPJOPH

DOI: https://doi.org/10.3126/nepjoph.v13i2.30707

Copyright $\odot 2021$ Nepal Ophthalmic Society

ISSN: 2072-6805, E-ISSN: 2091-0320

This work is licensed under a Creative Commons

Attribution-NonCommercial-NoDerivatives 4.0 International License (CC BY-NC-ND). 


\section{INTRODUCTION}

Rhegmatogenous retinal detachment (RRD) is a full thickness break of the retina caused by vitreous traction that can be potentially blinding. Hence, management algorithms have been proposed to guide retinal surgeons to opt for efficacious, cost effective treatments. (VelezMontoya et al, 2016). The management of RRD includes vitrectomy, pneumatic retinopexy (PR) and scleral buckling. However, case selection for these treatments and their effectiveness remains contentious (Hatef $\mathrm{E}$ et al, 2015). Uncomplicated RD with breaks in the superior 8 clock hours of retina are treated with PR with good outcome. However, maintaining a specific head posture for one week after this procedure is essential and outcomes are more promising in phakic eyes compared to pseudophakic and aphakic eyes (Chen CK et al, 2008) \& (Seo YS et al, 2016). The success rate of a single procedure is $74.4 \%$ however, additional surgery after the primary procedure results in a $96 \%$ success rate (Tornambe PE et al, 1991). Different gases are used for PR including, octa-fluoro-propane Gas (C3F8), sulfur hexafluoride $\mathrm{SF}_{6}$ and air. Air is less effective in the short-term but results in similar rates of reattachment over the long-term (Sinawat S et al, 2010).

A study from a tertiary eye hospital in central Saudi Arabia reported successful reattachment in $70 \%$ of 65 cases managed with PR (Hazzazi MA \& Al Rashaed S, 2007). To the best of our knowledge, there are no other peer reviewed literature on the management of RRD with PR from any other institution in Saudi Arabia.
In this study we present the clinical presentation and short term outcomes of cases with uncomplicated RRD managed with initial PR at a tertiary eye hospital in western Saudi Arabia.

\section{MATERIALS AND METHODS}

This one-armed cohort study evaluated patients who underwent primary PR for managing uncomplicated RRD. The institutional research board approved this retrospective cohort study. Written informed consent was obtained from all participants and this study adhered to the Declaration of Helsinki. Patients were included if they were evaluated by an experienced retinal surgeon who performed an extensive evaluation to determine they were candidates for primary PR. The inclusion criteria were retinal breaks within 8 to 4 o'clock, single or multiple breaks within 1 clock hour, eyes with minimal media opacity, patient stable to maintain positioning for 5-8 days after the procedure and no or grade 1 proliferative vitreoretinopathy (PVR). Patients were excluded if they declined to participate in the study, had a retinal break in a location other than the superior quadrant, severe glaucoma, media opacity, were noncooperative or scheduled to travel within 2 months postoperatively.

The steps in this study have been previously described (Mandelcorn ED et al, 2015) (Stewart S \& Chan W, 2018). Briefly, a detailed clinical examination was performed using slit lamp biomicroscopy with a +90 D lens. All efforts were directed at identifying and 
locating the retinal breaks. A chart was drawn in relation to the clock positions to demarcate retinal vasculature and retinal breaks. Optical coherence tomography (OCT) (Zeiss OCT system, USA) was performed to determine the retinal layers involved in the detachment and the presence and extent of subretinal fluid. PR was performed after delivering $2 \mathrm{ml}$ of $2 \%$ lidocaine via a sub-Tenon injection. In the surgical room, the surgeon once again visualized the retinal breaks using a binocular indirect ophthalmoscope (Heine, Germany). Using the retinal drawing as a reference and direct visualization of retinal break, laser was applied to seal the edges of the retinal break. An anterior chamber paracentesis was created using a $27 \mathrm{G}$ needle to aspirate approximately $0.2 \mathrm{ml}$ of aqueous. A $30 \mathrm{G}$ needle attached to prefilled syringe was inserted $3.5 \mathrm{~mm}$ posterior to the limbus in pseudophakic eyes and $4 \mathrm{~mm}$ away from limbus in phakic eyes, perpendicular to the sclera to reach the middle of the vitreous cavity. The needle was withdrawn so that 2 to 3 $\mathrm{mm}$ of shaft remained in the vitreous cavity, and 0.5 to $0.6 \mathrm{ml}$ of pure $\mathrm{SF}_{6}$ or $\mathrm{C}_{3} \mathrm{~F}_{8}$ gas was pushed briskly to ensure avoiding fish egg formation of gas bubble.

The operating surgeon then visualized the optic nerve head to review perfusion. If it was not perfused, the paracentesis was repeated. To avoid macular detachment, in selective cases a steamroller maneuver was performed (Mahdavi P \& Tornambe PE, 2017). After inserting gas, the head position was slowly rotated in a manner that the gas bubble was pressing onto the macula initially and it moved slowly towards the side with the detached retina and retinal break.

Based on the location of the retinal break, head posture was maintained for seven days postprocedure so that the gas bubble acts as an endotamponade to keep the break close to the outer structures of the eye. Patients were prescribed a topical steroid and cycloplegic. The retina was evaluated on day 1, 1 week, 6 weeks and 6 months after PR. At each postoperative visit, the IOP, status of the gas bubble, retinal break and $\mathrm{RD}$ were evaluated.

Anatomical success was defined as reattachment of the retina at 6 months after the PR procedure. Functional success was defined as improving visual acuity better than $20 / 200$ at 6 months postoperatively. If pre-PR laser and PR were the only procedures performed, it was considered a complete success. A qualified success was defined as a case that required an additional surgical procedure like scleral buckling or pars plana vitrectomy after PR and success was achieved.

Data were collected on the complications such as an IOP $>22 \mathrm{mmHg}$, gas entrapment in the anterior hyaloid, reattachment, development of new retinal breaks, progression of cataract, endophthalmitis, presence of gas in an abnormal position (anterior chamber, suprachoroidal space, subconjunctival space and development of proliferative vitreoretinopathy (PVR). 
The data were collected on each patient using a pretested data collection form. It was then transferred into a Statistical Package for Social Studies spreadsheet (SPSS 25) (IBM, Armonk, NY,USA). Univariate analysis using a parametric method was performed. Qualitative variables were presented as frequencies and percentage proportions. The quantitative variables, if normally distributed, were presented as the mean and standard deviation. If not distributed normally, the median and interquartile range was estimated. To associate success to known risk factors we estimated a relative risk, 95\% confidence interval and a two-sided $P$ value. $P$ $<0.05$ was considered statistically significant.

\section{RESULTS}

The study sample consisted of 15 cases of RRD in the superior quadrants that were managed with PR as the initial treatment (primary surgery). Table 1 presents the patient demographics and ocular status.

Table 1: Demographics and ocular status at presentation of patients with rhegmatogenous retinal detachment with breaks in the superior retina.

\begin{tabular}{|c|c|c|c|}
\hline \multirow{2}{*}{ Age (years) } & Mean & \multicolumn{2}{|l|}{49.0} \\
\hline & Standard deviation & \multicolumn{2}{|l|}{15.3} \\
\hline \multirow{2}{*}{ Duration of symptoms (Days) } & Median & \multicolumn{2}{|l|}{0.4} \\
\hline & Inter quartile range & \multicolumn{2}{|l|}{$0.14 ; 1.0$} \\
\hline Qualitative Variables & & Number & Percentage \\
\hline \multirow{2}{*}{ Gender } & Male & 8 & 53.3 \\
\hline & Female & 7 & 46.7 \\
\hline \multirow{2}{*}{ Eye involved } & Right eye & 9 & 60 \\
\hline & Left eye & 6 & 40 \\
\hline \multirow{4}{*}{ Systemic comorbidity } & Hypertension & 4 & 26.7 \\
\hline & Diabetes & 6 & 40.0 \\
\hline & Asthma & 2 & 13.3 \\
\hline & Systemic lupus erythematosus & 2 & 13.3 \\
\hline \multirow{4}{*}{ Lens status } & Phakia & 3 & 20 \\
\hline & Aphakia & 1 & 6.7 \\
\hline & Pseudophakia & 8 & 53.3 \\
\hline & Lens opacity & 3 & 20 \\
\hline \multirow{2}{*}{ Past history } & Post capsular tear & 0 & 0.0 \\
\hline & Retinal tear & 3 & 20 \\
\hline
\end{tabular}




\begin{tabular}{|c|c|c|c|}
\hline \multirow{2}{*}{ Macula involved in RRD } & Yes & 9 & 60 \\
\hline & No & 6 & 40 \\
\hline \multirow{2}{*}{ Vitreous hemorrhage } & Present & 0 & 0 \\
\hline & Absent & 15 & 100 \\
\hline \multirow{5}{*}{$\begin{array}{l}\text { Proliferative vitreoretinopathy } \\
\text { (PVR) }\end{array}$} & Absent & 13 & 86.7 \\
\hline & Present & 2 & 13.3 \\
\hline & Grade 1 & 1 & 6.7 \\
\hline & Grade 2 & 0 & 0.0 \\
\hline & Grade 3 & 1 & 6.7 \\
\hline \multirow{2}{*}{ IOP before } & Mean & \multicolumn{2}{|c|}{13.0} \\
\hline & Standard deviation & \multicolumn{2}{|c|}{3.0} \\
\hline \multirow{3}{*}{$\begin{array}{l}\text { Extent of retinal detachment } \\
\text { (o'clock) }\end{array}$} & Number of eyes & \multicolumn{2}{|c|}{12} \\
\hline & Median & \multicolumn{2}{|c|}{1.5} \\
\hline & Inter quartile range & \multicolumn{2}{|c|}{$1.0 ; 3.0$} \\
\hline
\end{tabular}

Table 2: Ophthalmic status six months after pneumatic retinopexy.

\begin{tabular}{|l|c|c|c|}
\hline \multirow{2}{*}{ IOP after } & Mean & \multicolumn{2}{|c|}{13.2} \\
\cline { 2 - 4 } & Standard deviation & \multicolumn{2}{|c|}{2.8} \\
\hline \multirow{2}{*}{ Residual subretinal fluid } & & Number & $\%$ \\
\cline { 2 - 4 } & Present & 7 & 46.7 \\
\hline \multirow{2}{*}{ Epi-retinal membrane } & Absent & 8 & 53.3 \\
\hline \multirow{2}{*}{ Cataract progression } & Present & 1 & 6.7 \\
\hline \multirow{2}{*}{ Proliferative vitreoretinopathy } & Absent & 14 & 93.3 \\
\hline \multirow{2}{*}{ Macular edema } & Yes & 1 & 6.7 \\
\cline { 2 - 4 } & No & 4 & 93.3 \\
\hline Glaucoma & Yes & 4 & 26.7 \\
\hline Endophthalmitis & No & 11 & 63.3 \\
\hline Macular hemorrhage & Yes & 3 & 20 \\
\hline Detachment of pigment epithelium & & 12 & 80 \\
\cline { 2 - 4 } & & 0 & 0.0 \\
\hline
\end{tabular}


Seven eyes received laser treatment to seal a retinal break just prior to the PR procedure. $\mathrm{SF}_{6}$ was used in one eye and $\mathrm{C} 3 \mathrm{~F} 8$ gas was used in 14 eyes.

At six months postoperatively, residual subretinal fluid $(7 ; 46.7 \%)$, epi-retinal membrane $(1 ; 6.7 \%)$, progression of cataract $(1 ; 6.7 \%)$, proliferative retinopathy $(4 ; 26.7 \%)$ and macular edema $(3,20 \%)$ was noted and managed through postural alteration, rest and oral steroids as presented in Table 2. None of the eyes had glaucoma, endophthalmitis, detached retinal pigment epithelium or macular hemorrhage.

The anatomic reattachment of the retina was noted in 11 of 15 eyes at six months postoperatively. The absolute anatomical success rate was $73.3 \%$ [95\% CI (confidence interval) 51.0: 95.7].

Of the 15 eyes with severe visual impairment before intervention, 5 (33.3\%) eyes had vision $>20 / 200$ at six months postoperatively. Absolute functional success was noted in $33.3 \%$ (95\% CI $9.5 ; 57.2)$ of cases.

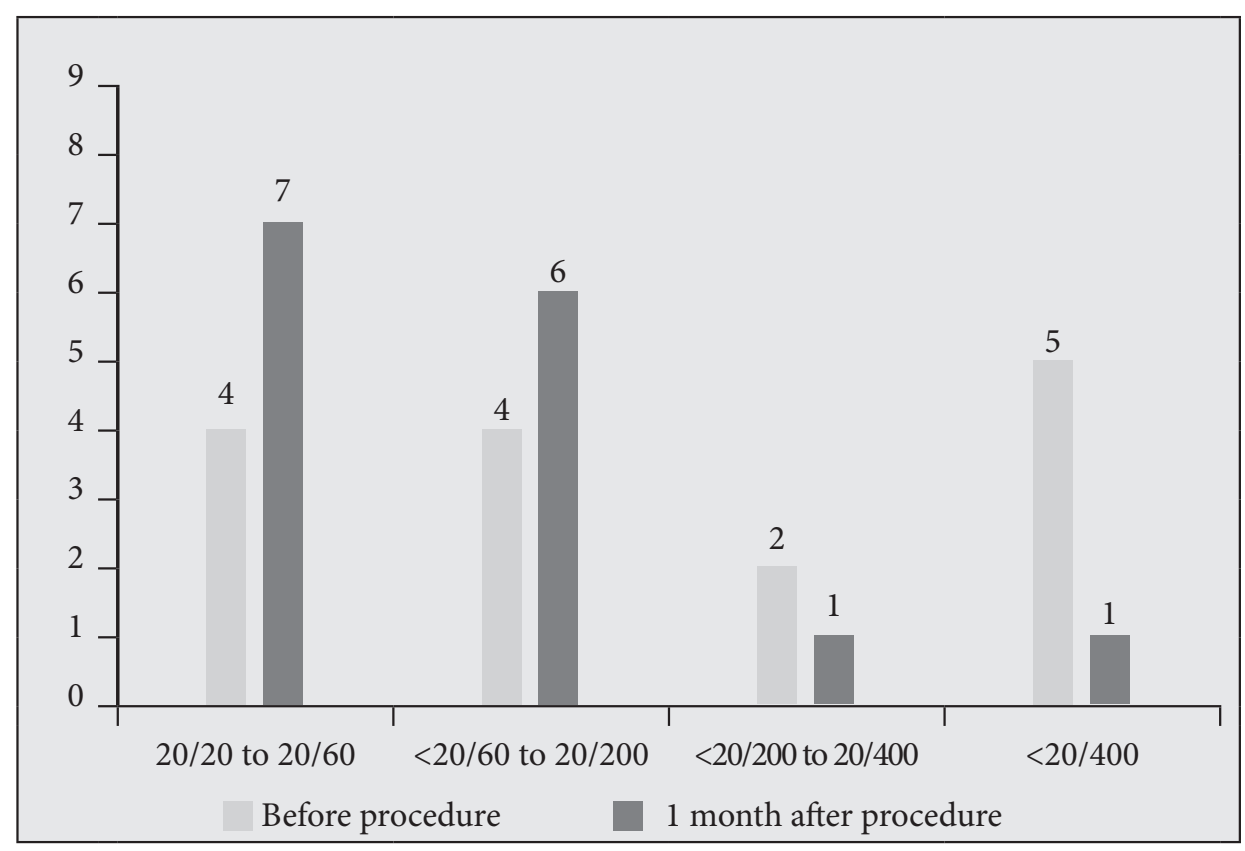

Figure 1: Comparison of visual impairment status before and six month after pneumatic retinopexy to manage retinal detachment.

$\mathrm{X}$ axis denotes visual impairment status

Y axis denotes number of eyes

Blue column denotes before the procedure (pneumatic retinopexy) and the red column denotes one month after the procedure. 


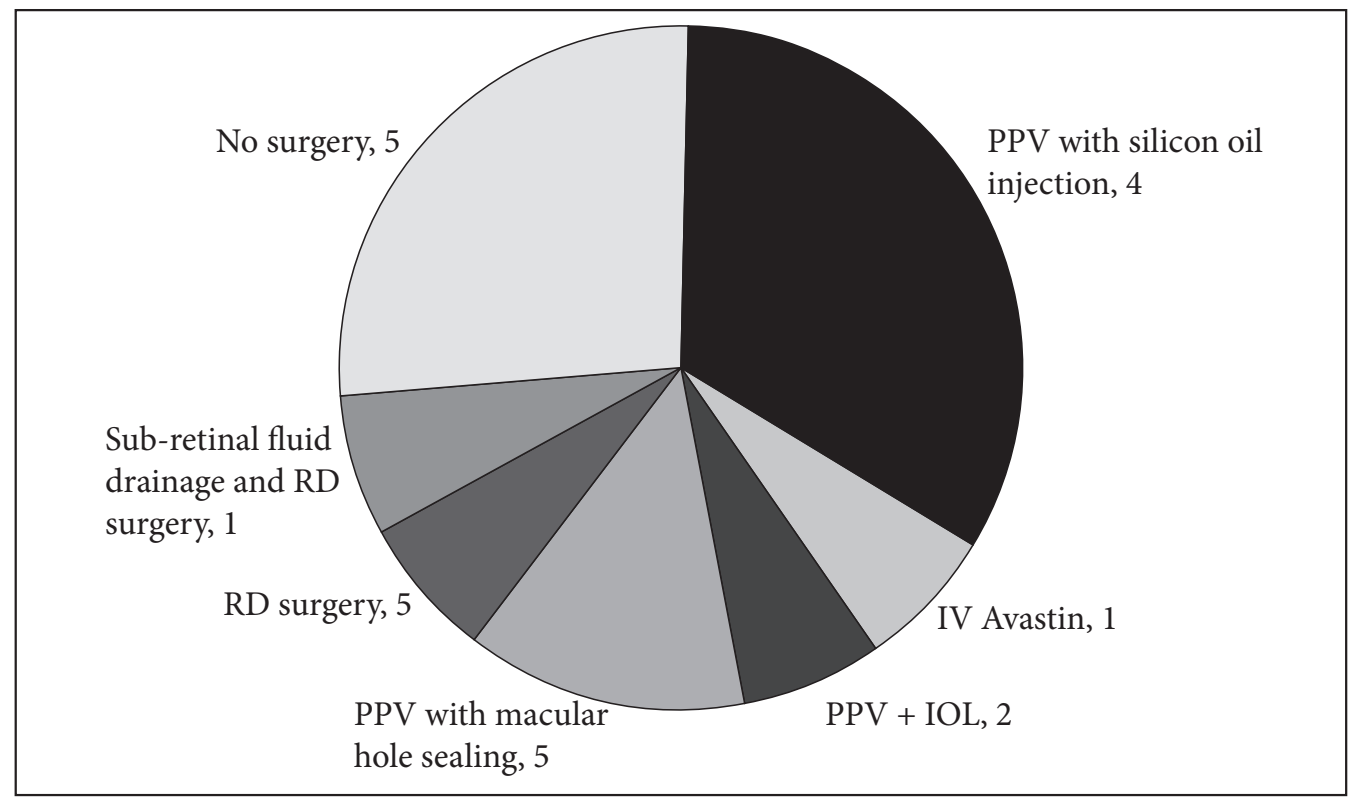

Figure 2: Additional procedures needed to manage eye with retinal detachment treated by pneumatic retinopexy before six months.

Figure 1 compares the preoperative BCVA to postoperative six months. Functional success of gaining vision better than 20/200 was noted in 13 of $15(86.7 \%)$ eyes $(95 \%$ CI $69.2 ; 100)$ at 6 months postoperatively.

In five eyes (33.3\%), no additional surgery was required, 7 eyes required PPV, and 1 eye required intravitreal injection of anti-vascular growth factor and repeat surgery for RD.

Retinal surgery was performed under general anesthesia in 5 eyes, $33.3 \%$ (95\% CI 9.5 ; 57.2). The data for an association of anatomical success to the lens status was evaluated. Among 11 eyes with anatomical success, the lens status was phakic (3), aphakic (1) and pseudophakic (7). In contrast, those with visible retinal detachment after surgery, lens status was phakic (3), aphakic(0) and pesudophakic (1) respectively. There was no significant association of the outcome to lens status [RR $=4.5$ (95\% CI 0.6 ; 37.5) $P=0.1]$.

We evaluated the data for an association between anatomic success to additional laser treatment for sealing retinal breaks. In 11 eyes with anatomical success, 6 (54.5\%) eyes had laser treatment before PR. In 4 eyes with detachment, $1(25 \%)$ eye had laser treatment. There was no significant association between a successful outcome and additional laser treatment. $[\mathrm{RR}=$ 1.7 (95\% CI $0.7 ; 4.0), P=0.2]$.

We evaluated the data for an association between anatomic success and preoperative macular involvement in retinal detachment. Of the 11 eyes with anatomical success, 7 (63.6\%) eyes 
飬

NEPiog 


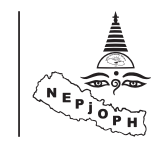


after PR (Velez-Montoya R et al, 2016) (Narendran V \& Kothari AR, 2014).

\section{CONCLUSION}

$\mathrm{PR}$ is standard procedure and in the era of newer modalities of surgical treatment and is less popular among vitreoretinal surgeons. However, in selected cases of RRD, PR is the most effective and an ideal initial procedure in remote locations where referral to a retinal surgeon may be challenging. Applications of special gas induced tamponade seems to prevent seepage of fluid through the break and allow adequate time for chorioretinal adhesion to occur after laser photocoagulation.

\section{REFERENCES}

Chan CK, Lin SG, Nuthi AS, Salib DM (2008). Pneumatic retinopexy for the repair of retinal detachments: A comprehensive review (1986-2007). Survey of ophthalmology;53(5):443-78. doi: 10.1016/j.survophthal.2008.06.008; PMid:18929759

Dhami A, Shah KK, Ratra D (2018). Pneumatic retinopexy outcomes as primary or secondary surgical option for treating rhegmatogenous retinal detachment. Indian Journal of Ophthalmology;66(3):420-5.

Gilca M, Duval R, Goodyear É, Olivier S, Cordahi G (2014). Factors associated with outcomes of pneumatic retinopexy for rhegmatogenous retinal detachments: A retrospective review of 422 cases. Retina;34(4):693-9. doi: 10.1097/IAE.0b013e3182a2e6ee; PMid:23974997

Hatef E, Sena DF, Fallano KA, Crews J, Do DV (2015). Pneumatic retinopexy versus scleral buckle for repairing simple rhegmatogenous retinal detachments. Cochrane Database of Systematic Reviews;(5). doi: 10.1002/14651858. CD008350.pub2; PMid:25950286

Hazzazi MA, Al Rashaed S (2017). Outcomes of pneumatic retinopexy for the management of rhegmatogenous retinal detachment at a tertiary care center. Middle East African Journal of Ophthalmology;24(3):143-7. doi: 10.4103/ meajo.MEAJO_137_15; PMid:29279655

Hillier RJ, Felfeli T, Berger AR, Wong DT, Altomare F, Dai D, et al (2019). Pneumatic retinopexy versus vitrectomy for the management of primary rhegmatogenous retinal detachment outcomes randomized trial (PIVOT). Ophthalmology, 126(4), 531-539. doi: 10.1016/j.ophtha.2018.11.014; PMid:30468761

Ling J, Noori J, Safi F, Eller AW (2018). Pneumatic retinopexy for rhegmatogenous retinal detachment in pseudophakia. In Seminars in Ophthalmology. 33(2):198-201.

Mandelcorn ED, Mandelcorn MS, Manusow JS (2015). Update on pneumatic retinopexy. Current Opinion in Ophthalmology;26(3):194-9. doi: 10.1097/ICU.0000000000000148; PMid:25784106

Mahdavi P, Tornambe PE (2017). Pneumatic Retinopexy 2. In Operative dictations in Ophthalmology (pp. 277-279). Springer, Cham. doi: 10.1007/978-3-319-45495-5_62 
Modi YS, Epstein A, Flynn HW, Shi W, Smiddy WE (2014). Outcomes and complications of pneumatic retinopexy over a 12-year period. Ophthalmic Surgery, Lasers and Imaging Retina, 45(2), 132-137. doi: 10.3928/2325816020140306-06; PMid:24635154

Narendran V, Kothari AR (2014). Intraocular gases In Principles and Practice of Vitreoretinal surgeries. Jaypee Brothers Medical Publishers, New Delhi, India. pp: 136-44. doi: 10.5005/jp/books/12210_18

Seo YS, Jang JW, Kim JM, Chang MH (2016). A Result of Pneumatic Retinopexy for Pseudophakic Retinal Detachment. Journal of the Korean Ophthalmological Society;57(6): 935-40. doi: 10.3341/jkos.2016.57.6.935

Sinawat, S., Ratanapakorn, T., Sanguansak, T., Prompol, S., Laopaiboon, M., \& Yospaiboon, Y (2010). Air vs perfluoropropane gas in pneumatic retinopexy: a randomized noninferiority trial. Archives of Ophthalmology;128(10):1243-7. doi: 10.1001/archophthalmol.2010.230; PMid:20937993

Stewart, S., \& Chan, W (2018). Pneumatic retinopexy: patient selection and specific factors. Clinical Ophthalmology (Auckland, NZ);12:493. doi: 10.2147/OPTH.S137607; PMid:29588570

Tornambe PE, Hilton GF, Brinton DA, Flood TP, Green S, Grizzard WS (1991). Pneumatic Retinopexy: Twoyear Follow-up Study of the Multicenter Clinical Trial Comparing Pneumatic Retinopexy with Scleral Buckling. Ophthalmology;98(7):1115-23. doi: 10.1016/S0161-6420(91)32168-7 